\title{
DISIPLIN SHALAT JAMAAH PARA PEDAGANG MUSLIM DI PUSAT NIAGA PALOPO
}

\author{
M. Said Mahmud \\ Institut Agama Islam Negeri (IAIN) Palopo \\ E-mail: saidmahmud@iainpalopo.ac.id
}

\begin{abstract}
This research is a qualitative research that discusses the issue of commitment among Muslim traders at the Center of Commerce Palopo on pray congregationally. The main issue discussed in this research is whether there is a commitment among Muslim traders at Palopo Trade Center in the implementation of pray congregationally?, and if any, how far is the effect of such disciplinary commitment in establishing silaturrahim and in improving their business result as a trader? The results showed that the implementation of the congregational prayers performed by traders at the Palopo Trading Center can be categorized as part of the factor of the formation of integration behavior, this is supported by the commitment and discipline. Discipline in prayer congregation for traders Palopo City Commercial Center against work ethic is done by: get used to unite and help; perfecting the prayers of the less worshipers; gain the good of the world; enliven sense of equality and brotherhood; familiarize people with their leaders; gain the good of religion; helps concentration of mind.
\end{abstract}

Keywords : muslim traders, pray congregationally, commercial center of Palopo city

\begin{abstract}
Abstrak
Penelitian ini adalah penelitian kualitatif yang membahas tentang masalah komitmen di kalangan para pedagang Muslim di Pusat Niaga Palopo dalam pelaksanaan ibadah shalat jamaah. Masalah pokok yang dibahas penelitian ini adalah adakah komitmen di kalangan para pedagang Muslim di Pusat Niaga Palopo dalam pelaksanaan ibadah shalat jamaah?, dan jika ada, sejauh mana pengaruh komitmen kedisiplinan tersebut dalam upaya menjalin silaturrahim serta dalam peningkatan hasil usaha mereka sebagai pedagang? Hasil penelitian menunjukkan bahwa pelaksanaan shalat berjama'ah yang dilakukan oleh pedagang di Pusat Niaga Palopo dapat dikategorikan sebagai bagian dari faktor pembentukan perilaku integrasi, hal ini didukung oleh komitmen dan kedisiplinan. Kedisiplinan dalam shalat berjama'ah bagi pedagang Pusat Niaga Kota Palopo terhadap etos kerja dilakukan dengan cara: membiasakan bersatu dan tolong menolong; menyempurnakan shalat orang-orang yang kurang ibadatnya; memperoleh kebaikan dunia; menghidupkan rasa persamaan dan persaudaraan; membiasakan umat mentaati pemimpin-pemimpinnya; memperoleh kebaikan agama; membantu konsentrasi pikiran.
\end{abstract}

Kata Kunci: shalat jamaah, pedagang muslim, pusat niaga kota palopo

\section{PENDAHULUAN}

Telah menjadi Sunnatullah (ketentuan Allah swt.) bahwa setiap target yang ingin dicapai oleh seseorang mesti dikejar dengan memelihara kedisiplinan. Sedang kedisiplinan itu sendiri dapat dimaknai antara lain dalam bentuk ketepatan waktu, di samping pelaksanaan pekerjaan dengan memanfaatkan hukum alam (sebab akibat) secara benar. 
Allah swt., menampakkan tanda keMaha Penyayangan dalam rangka mengarahkan hamba-hamba Nya agar terbiasa dengan budaya disiplin. Yaitu melalui penetapan kewajiban pelaksanaan ibadah shalat fardhu sebanyak lima kali dalam kurun waktu sehari semalam. Selain itu, Allah swt. juga mendorong para hamba Nya yang berkomitmen menunaikan ibadah shalat fardhu lima kali sehari semalam tersebut agar melaksanakannya secara berjamaah di masjid. ${ }^{1}$ Salah satu dari sekian banyak tujuan pelaksanaan ibadah shalat jamaah ialah agar tercapai peningakatan kualitas misalnya untuk mendapatkan pahala yang lebih istimewa yaitu mencapai keistimewaan 27 derajat jika dibandingkan dengaan ibadah shalat yang dilaksanakan secara munfarid (seorang diri).

Selain nilai tambah yang diberikan kepada pelaksana ibadah shalat jamaah sebagaimana yang disebutkan di atas, sungguh masih banyak kelebihan yang menyertainya. Antara lain terwujudnya hubungan sosial yang kokoh di kalangan para anggota jamaah karena setiap mereka bersua di saat pelaksaaan shalat jamaah di masjid, tentu saja disertai dengan kontak pribadi yang tentunya akan bermuara pada suasana saling mencintai secara positif lalu berlanjut dengan saling mengisi dan saling tukar informasi yang menguntungkan.

Realitas kehidupan yang dialami umat Islam yang taat beribadah, terutama bagi mereka yang menunaikan ibadah shalat secara berjamaah di masjid, menunjukkan bahwa hubungan silaturrahim (rasa saling menyayangi) di antara mereka para warga jamaah tersebut jauh lebih kuat, bahkan jauh lebih luas jika dibandingkan dengan hubungan pribadi antar individu yang tidak memelihara tradisi pelaksanaan ibadah shalat jamaah di masjid. Dengan demikain, jalur pergaulan dalam kehidupan duniawi semakin bertambah luas dan peluang untuk mendapatkan rezeki pun semakin terbuka lebar.

Para pedagang sebagai bagian dari warga masyarakat pelaku bisnis yang menggantungkan nasib keberuntungan mereka pada kuantitas relasi secara maksimal, seharusnya menjadikan budaya disiplin shalat jamaah

${ }^{1}$ Sidi Gazalba dalam hal ini menyatakan bahwa fungsi masjid terutama di zaman nabi Muhammad saw di samping sebagai pusat ibadah, juga sebagai pusat kebudayaan termasuk urusan pendidikan dan urusan pengembangan ekonomi umat Islam. Lihat : Sidi Gazalba, Masjid Pusat Iabadah dan Kebudayaan Islam, (cet. V; Jakarta: Pustaka Al-Husna, 1989), h. 127 - 128. Sementara itu Nazaruddin Umar (Wakil Menteri Agama R.I.) menekankan bahwa di zaman nabi Muhammad sws memimpin umat di Madinah, masjid memiliki fungsi sampai 15 macam. Di antaranya : pusat ibadah, pusat pendidikan, pusat kegiatan politik dan pemerintahan, pusat kegiatanperencanaan ekonomi, dan pusat pengaturan hubungan luar negeri. (Nazaruddin Umar, wawancara via telefon, hari Sabtu tgl 03 Maret 2012, pkl 07. 40 sd 07.55 Wita). Di pihak lain, Quraish Shihab menjelaskan bahwa masjid dalam pengertian sehari-hari adalah bangunan tempat shalat, dan masjid pada hakikatnya adalah tempat melakukan segala aktivitas yang mengandung kepatuhan kepada Allah semata. Lihat: Quraish Shihab, Wawasan al-Qur'an, Tafsir Maudhui terhadap Pelbagai Persoalan Umat, (cet. VIII; Bandung: Mizan, 1998), h. 460. 
sebagai bagian yang tak terpisahkan dari kegiatan hidup mereka. Sebab dalam kesempatan pelaksanaan ibadah shalat jamaah tersebut, tercapai berbagai keuntungan yang sungguh amat diperlukan oleh setiap pelaku bisnis dalam upaya untuk meraih keuntungan dan hasil usaha yang diidam-idamkan.

Siapapun yang menekuni bidang bisnis, termasuk yang berkecimpung di dunia perdagangan, harus pandai-pandai untuk menjangkau relasi sebanyak mungkin dan mampu memperluas cakrawala pergaulan. Modal utama yang amat perlu dipelihara ialah kemampuan menjalin Silaturrahim agar simpati pihak-pihak yang dijadikan sebagai mitra pergaulan dapat diraih seluas mungkin. Simpati dari pihak mitra interaksi itu justru merupakan modal immaterial utama dan paling utama yang perlu dimiliki sebelum pengembangan usaha bisnis dalam pemanfaatan modal material berupa dana atau modal keuangan. Di sinilah letak jawaban atas pertanyaan mengapa para pelaku bisnis sangat perlu untuk meraih simpati dari berbagai pihak secara maksimal. Jalan untuk dapat meraih simpati berbagai pihak ialah dengan menunjukkan empati secara tulus kepada siapa saja terutama pihak-pihak yang berpotensi untuk dijadikan sebagai mitra dalam pengembangan dunia usaha.

Salah satu kiat yang ditunjukkan oleh Rasulullah, Muhamad saw. dalam berinteraksi di berbagai bidang kegiatan hidup agar diperoleh simpati dari pihak-pihak yang dijadikan sebagi mitra interaksi ialah menunjukkan sikap lemah lembut. Diriwayatkan bawa beliau bersabda :

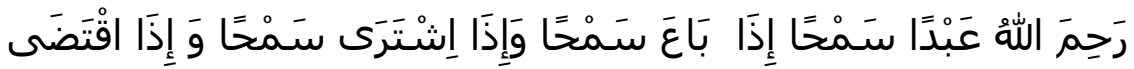

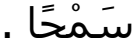

Artinya:

Allah swt. menyayangi seorang hamba yang bersikap lemah lembut. Jika ia menjual ia bersikap lemah lembut dan jika ia membeli ia pun bersikap lemah lembut. Dan jika ia memutuskan suatu perkara, ia pun bersikap lemah lembut)

Sebagai sosok pedagang dan sekaligus teladan yang terbaik dalam segala hal, ${ }^{2}$ termasuk di dalamnya kegiatan menjalankan roda perdagangan, Rasulullah, Muhammad saw. memberikan teladan terbaik tentang cara berdagang terutama dalam melayani para pelanggan bisnis dalam mengelola komoditas perdagangan yang telah diamanahkan sepenuhnya oleh Khadijah r.a. kepada beliau di saat usianya baru berkisar 25 tahun, keuntungannya berlipat ganda dan para relasi yang pernah berinteraksi dengan beliau sama-

${ }^{2}$ Al-Qur'an al-Karim, surah al-Ahzab (33) : 21. 
sama merasa puas berkat sikap lembut dan keramahan yang beliau tunjukkan. ${ }^{3}$

Keramahan dan kelembutan dalam berinteraksi akan selalu terpupuk melalui pertemuan dan kegiatan interaksi sosial. Termasuk di dalamnya kegiatan dalam perdagangan. Para pedagang pun selalu menginginkan agar pelanggan mereka semakin bertambah sebab hal itu merupakan pembuka pintu rezeki. Dapat dipastikan bahwa pelaku bisnis yang paling ramah dalam pelayanan, atau yang paling simpatik dalam pergaulan, itulah yang paling berpotensi untuk lebih banyak menarik perhatian para pelanggan untuk menjadi mitra dalam usaha mereka.

Tempat dan waktu yang paling tepat bagi para pedagang Muslim untuk memupuk semangat kebersamaan, sekaligus menunjukkan keramahan dalam pergaulan keseharian, ialah masjid pada setiap waktu pelaksanaan shalat jamaah. Sedang bagi para pedagang Muslim yang menekuni kegiatan mereka sebagai pelaku bisnis di Pusat Niaga Palopo (PNP), sepantasnya menunjukkan kesyukuran sebab fasilitas tempat ibadah shalat jamaah setiap waktu shalat sudah tersedia di sekitar tempat tersebut. Ada dua buah masjid yang cukup representatif di lokasi itu. Keduanya masing-masing ialah, pertama masjid AlFurqan di bagian utara yang hanya diantarai oleh jalan raya dan jaraknya hanya sekitar 40 (empat puluh) meter dari pintu utama bagian utara pasar besar tersebut. Kedua, masjid Al-Barakah di bagian selatan yang letaknya masih dalam lokasi terminal yang berhubungan langsung dengan kompleks pasar sentral Palopo tersebut.

Pusat kegiatan para pedagang Muslim di Pasar Sentral Palopo berada di antara kedua masjid yang tersebut di atas. Jarak antara tempat kegiatan mereka dengan kedua tersebut paling jauh hanya sekitar 200 (dua ratus) meter. Artinya, jika para pedagang Muslim di pusat kegiatan perniagaan itu mau berjalan kaki ke salah satu masjid untuk melaksanakan ibadah shalat secara berjamaah, maka waktu yang mereka butuhkan tidak lebih dari 10 (sepuluh) menit dan tentu saja suasana segar bugar menyertai mereka sebab jalan kaki pergi-pulang antara tempat kegiatan dan masjid terdekat, sekaligus merupakan gerak badan yang meningkatkan vitalitas hidup jasmani dan ruhani. Kesegaran itu semakin meningkat lagi jika dilanjutkan dengan saling bertegur sapa antar para jamaah di masjid, baik di antara sesama kalangan pedagang Muslim maupun dengan sesama jamaah dari latar belakang profesi yang berbeda-beda. Penelitian ini berupaya uuntuk mengetahui tingkat dan kualitas kedisiplinan pelaksanaan shalat jamaah para pedagang Muslim di Pusat Niaga Palopo sebagai salah satu sarana untuk menjalin hubungan

${ }^{3}$ Muhyiddin, Mawlid Syarafa-Anam, Bandung, al-Maarif. T. th, hlm. 89. 
Silaturrahim sekaligus sebagai salah satu penyebab bertambah lebarnya lubang rezeki.

\section{METODE}

Studi ini merupakan penelitian lapangan (field research) yang berupaya untuk menjelaskan secara kualitatif tentang langkah-langkah penyadaran jamaah masjid, khususnya dari kalangan para pedagang Muslim yang secara konsisten melaksanakan shalat jemaah secara disiplin di celah-celah kegiatan mereka menekuni kegiatan perdagangan di Pusat Niaga Palopo. Selanjutnya, untuk memperkaya kajian dan untuk lebih menambah makna kerangka teori, peneliti menggunakan sejumlah literatur sebagai pendukung dalam analisis dan pemaparan dengan menggunakan pendekatan teologis-normatif dan pendekatan sosiologi komunikasi.

Pengumpulan data dilakukan dengan observasi langsung dan tidak langsung, melalui pengamatan di lapangan khususnya di kalangan komunitas jamaah masjid-masjid di kota Palopo. Selain itu digunakan pula wawancara terstruktur dan tidak terstruktur dengan menggunakan seperangkat instrumen penelitian berupa pertanyaan-pertanyaan tertulis sebagai pedoman dalam melakukan wawancara, ataupun hanya berupa garis-garis besar permasalahan yang akan ditanyakan, baik kepada kalangan pengurus masjid, tokoh agama, tokoh masyarakat muslim, maupun warga masyarakat yang tergolong sebagai jamaah masjid di kota Palopo maupun informan yang dipandang mengetahui kondisi di lokasi penelitian. Agar data hasil wawancara tidak hilang, maka disamping melakukan pencatatan hasil pembicaraan juga menggunakan alat perekam.

\section{KOMITMEN DAN KEDISIPLINAN PEDAGANG PUSAT NIAGA KOTA PALOPO DALAM SHALAT BERJAMAAH}

Untuk mengetahui komitmen dan kedisiplinan pedagang pusat niaga Kota Palopo terhadap pelaksanaan shalat berjama'ah terhadap perilaku sosial, terlebih dahulu memahami bagaimana cara pembentukan perilaku sosial keagamaan tersebut. Sedangkan berpengaruh dan tidaknya pelaksanaan shalat berjama'ah terhadap perilaku, maka perlu diketahui sejauhmana keutamaan dan aspek-aspek psikologis yang ada dalam shalat berjama'ah sehingga dapat memberikan motivasi kepada seseorang.

1. Pembentukan Perilaku Komitmen dan Kedisiplinan Pedagang Pusat Niaga Kota Palopo

Perilaku kedisiplinan secara garis besar dapat terbentuk melalui empat cara yaitu: Adopsi, deferensial, intregasi, trauma. Dari keempat cara tersebut, pelaksanaan shalat berjama'ah yang dilakukan oleh pedagang di Pusat Niaga Palopo yang menjadi jamaah di masjid Al-Furqan dan masjid Al-Barakah dapat 
dikategorikan termasuk sebagai faktor pembentukan perilaku integrasi. Caracara pembentukan perilaku integrasi diperoleh dari pelaksanaan kedisiplinan shalat berjama'ah.

2. Faktor Pendukung Komitmen dan Kedisiplinan shalat berjama'ah bagi Pedagang Pusat Niaga Kota Palopo

Di antara faktor pendukung komitmen dan kedisiplinan shalat berjama'ah bagi pedagang Pusat Niaga Kota Palopo adalah sebagai berikut:

a. Umumnya para pedagang di Pusat Niaga Kota Palopo yang menjadi jamaah di masjid Al-Furqan dan masjid Al-Barakah beranggapan bahwa Allah swt., mengangkat kedudukan bekas-bekas orang yang berjalan menuju masjid, sehingga malaikat berjejal saling berebutan dalam menetapkan dan mengangkat kelangit.

b. Para pedagang di Pusat Niaga Kota Palopo yang menjadi jamaah di masjid Al-Furqan dan masjid Al-Barakah beranggapan bahwa shalat berjama'ah salah satu sebab memperoleh jaminan hidup baik dan mati dalam kebaikan.

c. Para jamaah yang beprofesi sebagai pedagang tersebut beranggapan bahwa dengan shalat berjamaah, mereka mendapat jaminan dari Allah swt.

d. Shalat berjama'ah mempunyai nilai lebih dibandingkan dengan shalat secara sendirian dengan 27 derajat

e. Keutamaan yang besar bagi yang menempati shaf (barisan) terdepan antara lain: seperti shafnya para malaikat, Allah SWT dan para malaikat bershalawat untuk shaf yang paling depan

f. Kekaguman Allah swt kepada seseorang yang melakukan Shalat berjama'ah.

g. Diampuni segala dosa-dosa orang yang melakukan shalat berjama'ah.

Demikian alasan-alasan yang menjadi dasar komitmen dan kedisiplinan shalat berjama'ah bagi pedagang Pusat Niaga Kota Palopo. Anggapan mereka, shalat berjama'ah memberikan motivasi dan spirit bagi orang yang melaksanakannya, dengan obsesi untuk mendapatkan keutamaan tersebut tentunya ia akan melaksanakan shalat berjama'ah dengan baik.

\section{PENGARUH KEDISIPLINAN PEDAGANG PUSAT NIAGA KOTA PALOPO DALAM SHALAT BERJAMAAH TERHADAP PENINGKATAN ETOS KERJA}

Pengaruh kedisiplinan yang ada dalam shalat berjama'ah bagi pedagang Pusat Niaga Kota Palopo terhadap etos kerja antara lain: 
1. Membiasakan bersatu dan tolong menolong

Para pedagang di Pusat Niaga Kota Palopo yang menjadi jamaah di masjid Al-Furqan dan masjid Al-Barakah menganggap bahwa shalat berjamaah merupakan sebuah wujud persatuan antara sesama hamba Allah swt, hal ini melandasi mereka dalam melaksanakan profesi, sehingga wujud dari hal tersebut, mereka beranggapan bahwa perdagangan merupakan profesi yang didasari oleh tolong menolong antar sesama manusia. Pedagang menyediakan kebutuhan barang dan jasa yang diinginkan dan dibutuhkan oleh masyarakat, dan wujud terimakasih dari penyediaan barang dan jasa tersebut adalah melalui pemberian imbalan yang layak atas barang dan jasa yang mereka gunakan. Sebagaimana firman Allah swt dalam al-Qur'an Q.S. alMaidah ayat 2:
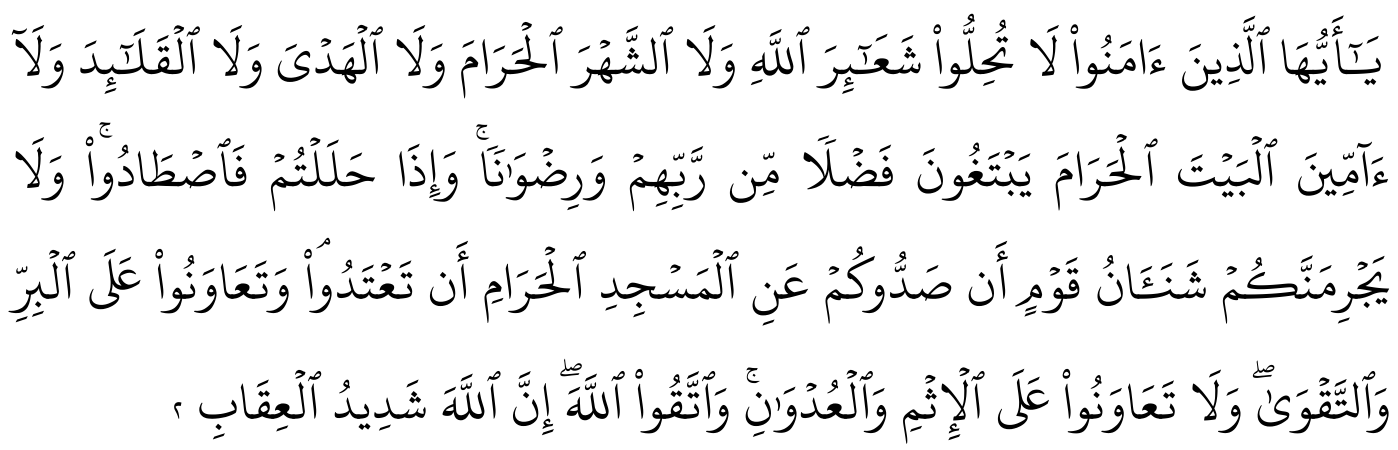

Terjemahnya:

Hai orang-orang yang beriman, janganlah kamu melanggar syi'ar-syi'ar Allah, dan jangan melanggar kehormatan bulan-bulan haram[390], jangan (mengganggu) binatang-binatang had-ya, dan binatang-binatang qalaa-id, dan jangan (pula) mengganggu orang-orang yang mengunjungi Baitullah sedang mereka mencari kurnia dan keredhaan dari Tuhannya dan apabila kamu telah menyelesaikan ibadah haji, Maka bolehlah berburu. dan janganlah sekali-kali kebencian(mu) kepada sesuatu kaum karena mereka menghalang-halangi kamu dari Masjidilharam, mendorongmu berbuat aniaya (kepada mereka). dan tolong-menolonglah kamu dalam (mengerjakan) kebajikan dan takwa, dan jangan tolong-menolong dalam berbuat dosa dan pelanggaran. dan bertakwalah kamu kepada Allah, Sesungguhnya Allah Amat berat siksa-Nya.

2. Menyempurnakan shalat orang-orang yang kurang ibadatnya

Mayoritas, masyarakat yang berprofesi sebagai seorang pedagang memiliki aktivitas sibuk sepanjang hari, mulai dari menggelar barang dagangan di pagi hari, melayani pembeli, hingga membereskan kembali dagangannya di sore hari. Hal ini juga menjadi ciri khas bagi para pedagang di Pusat Niaga Kota Palopo yang menjadi jamaah di masjid Al-Furqan dan masjid Al-Barakah. Kesibukan mereka yang menyita waktu bahkan hingga waktu 
ibadah, membuat mereka harus mampu hadir mengikuti shalat secara berjamaah untuk menyempurnakan ibadah-ibadah mereka yang kurang sempurna.

3. Kebaikan dunia.

Dengan berkumpulnya orang yang berdekat-dekatan rumah di dalam masjid selaku rumah Allah SWT, lima kali dalam satu hari untuk menyembah Allah SWT dan memperbaiki urusan-urusan dunia, mudahlah berhasilnya kebaikan bagi urusan dunia dan kejayaannya, karena berkenal-kenalan dan berkasih-kasihan itu membangkitkan rahmah dan syafaqah (kasih mengasihi) serta cinta mencintai antara sesama mereka.

4. Menghidupkan rasa persamaan dan persaudaraan

Kerjasama berarti bekerja bersama-sama untuk mencapai tujuan yang sama. Ia adalah suatu proses sosial yang paling dasar. Biasanya kerja sama melibatkan pembagian tugas, di mana setiap orang mengerjakan setiap pekerjaan yang merupakan tanggung jawabnya demi tercapainya tujuan yang sama

5. Membiasakan ummat mentaati pemimpin-pemimpinnya

6. Kebaikan agama.

Dengan berkumpulnya orang-orang alim dengan orang-orang yang jahil dalam mengerjakan shalat, menjadilah orang-orang jahil mengetahui, apa-apa yang tidak diketahuinya baik mengenai soal dunia, maupun soal akhirat. Begitu pula para pedagang, mereka yang berkumpul dengan berbagai unsur dan elemen masyarakat untuk saling berbagi ilmu dan pemahaman dalam keagamaan.

7. Dapat membantu konsentrasi pikiran.

Di samping perdagangan, para pedagang di Pusat Niaga Palopo itu sejuga melakukan berbagai kegiatan secara bersama-sama, baik bersih bersih pasar dan masjid, atau pekerjaan lainnya. Tiap pekerjaan yang dilakukan dengan bersama-sama akan menambah semangat orang yang melakukannya, serta timbulnya perasaan bahwa yang dikerjakan itu penting sehingga dorongan untuk mengerjakannya meningkat.

\section{PENUTUP}

Berdasarkan uraian dan pembahasan baik yang bersumber dari hasil penelitian kepustakaan maupun penelitian lapangan yang dilaksanakan dapat ditarik beberapa kesimpulan bahwa shalat berjama'ah yang dilakukan oleh pedagang di Pusat Niaga Palopo yang menjadi jamaah di masjid Al-Furqan dan masjid Al-Barakah dapat dikategorikan termasuk sebagai faktor pembentukan perilaku integrasi, hal ini didukung oleh faktor komitmen dan kedisiplinan. 
Selain itu, dapat pula disimpulkan bahwa pengaruh kedisiplinan dalam shalat berjama'ah bagi pedagang Pusat Niaga Kota Palopo terhadap etos kerja antara lain: membiasakan bersatu dan tolong menolong; menyempurnakan shalat orang-orang yang kurang ibadatnya; memperoleh kebaikan dunia; menghidupkan rasa persamaan dan persaudaraan; membiasakan umat mentaati pemimpin-pemimpinnya; memperoleh kebaikan agama; membantu konsentrasi pikiran.

\section{DAFTAR PUSTAKA}

Ashfahani, al-Raghib, al-.Mufradat Alfazh al-Qur'an Cet. I; Damsyiq: Dar alQalam, 1992.

Atmosudirjo, S. Prayudi. Dasar-Dasar Umum Administrasi, Jakarta: t.p.1979.

Ayub, Muh. E.. Manajemen Masjid Jakarta: Gema Insani, Press, 1996.

Baqi, Muhammad Fu'ad Abdul, al-. al-Mu'jam al-Mufahras li Alfaz al-Qur'an alKarim Bairut: Dar al-Fikr, 1992.

Buangin, Burhan, M.. Sosiologi Komunikasi, cet. IV; Jakarta: Prenada Media Group, 2009.

Bukhari, Abu Abdillah bin al-Mughirah al-Bardizbar, al-. Shahih al-Bukhari, juz VIII Semarang: Toha Putra, t.th..

Chaeri, Salahuddin dan Shadiq, Kamus Istilah Agama Cet. I; Jakarta: Sientarama, 1983,.

Departemen Agama RI. al-Qur'an dan Terjemahnya Jakarta: Proyek Pengadaan Kitab Suci al-Qur'an, 1992.

Gazalba, Sisdi. Masjid Pusat Iabadah dan Kebudayaan Islam, cet. V; Jakarta: Pustaka Al-Husna, 1989.

Hasibuan, Lukman Hakim. Pemberdayaan Masjid Masa Depan Cet. II; Jakarta: PT. Bina Rena Pariwara, 2003.

Harahap, Sofyan Syafri. Manajemen Masjid; Suatu Pendekatan Teoretis dan Organisatoris Cet. II; Yogyakarta: Danba Bhakti Prima Yasa, 1993.

Ma'luf, Louis,. al-Munjid fi al-Lughah Bairut: Dar al-Marsyid, 1977.

Pemerintah Kota Palopo, Palopo dalam Angka, Palopo, Badan Perencanaan Pemberdayaan Kota Palopo, 2012.

Poerwadarminta, WJS. Kamus Bahasa Indonesia Cet. II; Jakarta: Balai Pustaka, 1987.

Rasyidi, Ero H. Organisasi dan Manajemen Bandung: Alumni, 1975.

Ratna, Nyoman Khuta. Metodologi Penelitian Kajian Budaya dan Ilmu Sosial Humaniora pada Umumnya, Yogyakarta: Pustaka Pelajar, 2010,

Sanusi, Salahuddin. Pembahasan Sekitar Prinsip-Prinsip Dakwah Islam Semarang: Ramadhani, 1964.

Shihab, Quraish. Wawasan al-Qur'an, Tafsir Maudhui terhadap Pelbagai Persoalan Umat, cet. VIII; Bandung: Mizan, 1998.

Siagian, S. P. Filsafat Administrasi Jakarta: Gunung Agung, 1975. 
Sztompka, Poitr. Sisiologi Perubahan Sosial, cet. V; Jakarta: Prenada Media Group, 2010.

Tanzil, Hazil, dan Panglaykim,. Manajemen Suatu Pengantar Cet. XV; Jakarta: Ghalia Indonesia, 1991.

Tim Penulis IAIN Syarif Hidayatullah. Ensiklopedi Islam Jakarta: Djambatan, 1992.

Ya'kub, Hamzah. Manajemen Kepemimpinan Bandung: Diponegoro, 1984 